\title{
LOKABASA
}

Jurnal Kajian Bahasa, Sastra, dan Budaya Daerah serta Pengajarannya

Volume 11, No. 1, April - 2020, Hal. 1-9

p-2338-6193 (print) | e-2528-5904 (online)

Homepage: http://ejournal.upi.edu/index.php/lokabasa doi: https://doi.org/10.17509/jlb.v11i1

\section{Model Explicit Intruction dalam Materi Kawih Sunda}

\author{
Cica Zahra Nadia ${ }^{1}$, Rahman $^{2}$ \\ ${ }^{1}$ SMA Taman Siswa Bandung, ${ }^{2}$ Universitas Pendidikan Indonesia \\ cicazahra3440@gmail.com
}

\begin{abstract}
Sejarah Artikel: Diterima (15 Desember 2019); Diperbaiki (20 Januari 2020); Disetujui (05 Februari 2020); Published (30 April 2020)
\end{abstract}

Bagaimana mengutip artikel ini (dalam gaya APA): Nadia, C. Z. \& Rahman (2020). Model Explicit Intruction dalam Materi Kawih Sunda. Lokabasa, 11(1), 1-9. doi:

https://doi.org/10.17509/jlb.v11i1.25161

Abstrak: Penelitian ini dilatarbelakangi oleh kurangnya kemampuan siswa dalam ngawih Sunda. Tujuan dari penelitian ini adalah untuk mendeskripsikan kemampuan ngawih sebelum dan setelah menggunakan model Explicit Intruction, meningkat atau tidaknya setelah menggunakan model Explicit Intruction, serta mendeskripsikan perbedaan antara kemampuan ngawih sebelum dan setelah menggunakan model Explicit Intruction. Metode yang digunakan dalam penelitian ini yaitu metode kuasi eksperimen, kepada siswa kelas XI KPU-2 SMK Negeri 12 Bandung dengan menggunakan desain pretest dan post-test. Berdasarkan hasil penelitian yang dilaksanakan, rata -rata sebelum menggunakan model Explicit Intruction adalah $(30,14)$ yang membuktikan bahwa siswa belum mampu ngawih, sedangkan rata-rata setelah menggunakan model Explicit Intruction adalah $(75,88)$ yang membuktikan siswa mampu ngawih. Berdasarkan hasil uji statistika nilai signifikansi (Sig.2-tailed) yaitu $(0,000<0,5)$ atau kurang dari 0,5. Dengan demikian, $\mathrm{H}_{1}$ diterima serta $\mathrm{H}_{0}$ ditolak. Artinya ada perbedaan yang signifikan anatar kemampuan ngawih sebelum dan setelah menggunakan model Explicit Intruction. Hal ini menunjukan bahwa model pembelajaran Explicit Intruction dapat meningkatkan kemampuan ngawih Sunda siswa kelas XI KPU-2 SMK Negeri 12 Bandung Tahun Ajaran 2018/2019.

Kata Kunci: model Explicit Intruction; ngawih; kawih

\section{Model Explicit Intruction in Kawih Sunda Materials}

Abstract: This research is motivated by the lack of students' abilities in Sundanese. The purpose of this study is to describe the ability of ngawih before and after using the Explicit Intruction model, whether or not increasing after using the Explicit Intruction model, as well as describing the difference between the ngawih ability before and after using the Explicit Intruction model. The method used in this study is a quasi-experimental method, to students of class XI KPU-2 SMK Negeri 12 Bandung by using a pretest and post-test design. Based on the results of research conducted, the average before using the Explicit Intruction model is (30.14) which proves that students are not capable of being incompetent, while the average after using the Explicit Intruction model is (75.88) which proves students are capable of being incompetent. Based on the statistical test results the significance value (Sig.2-tailed) is (0,000 $<0.5)$ or less than 0.5. Thus, $\mathrm{Hl}$ is accepted and $\mathrm{HO}$ is rejected. This means that there is a significant difference between the ability to appear before and after using the Explicit Instruction model. This shows that the Explicit Intruction learning model can improve the Sundanese ngawih ability of class XI KPU2 students of SMK Negeri 12 Bandung in Academic Year 2018/2019.

Keywords: model Explicit Intruction; ngawih; kawih 


\section{PENDAHULUAN}

Dalam kurikulum kurtilas revisi 2017 (Kurikulum Tilu Belas) pembel-ajaran Bahasa Sunda di SMA/SMK salahasatunya ada materi kawih. Kawih Sunda merupakan warisan budaya yang harus dijaga supaya tidak hilang. Upaya pemerintah dalam menjaga budayanya yaitu dengan cara mempertahankan dalam dunia pendidikan. Begitu pula menurut Hendrayana (2017), untuk mencapai pola pembelajaran sangat di butuhkan perangkat pembelajaran yang menunjang kegiatan pembelajaran.

Berdasarkan KIKD Mata Pembelajaran Bahasa jeung Sastra Sunda Kurikulum 2013 Revisi 2017 jenjang SMA/SMK kelas X, ada beberapa point yang harus di sampaikan kepada siswa diantaranya, seperti yangtertera pada Kompetensi Dasar (KD) 4.4 "Melantun-kan kawih Sunda klasik dan Pop dengan memperhatikan ekspresi, dan teknik vokal".

Masalah yang ada saat ini di lapangan yaitu, ketika siswa diberi kesempatan untuk menerapkan materi kawih kebanyakan siswa merasa malu, serta belum berani untuk menyanyikan lagu Sunda. Salim Danny (2010, hlm. 24) mengutarakan, musik gamelan seharus-nya mempunyai pengaruh yang besar ketimbang musik-musik barat terbukti di lapangan, siswa lebih hafal lagu-lagu luar dari pada kawih Sunda, ketika di tes sudah susah memiliki cengkok urang Sunda-nya begitu pula malu dalam mengekspresikan ketika di tes ngawih.

Dalam pembelajaran, beberapa masalah sering dialami oleh guru. Untuk mengatasi berbagai masalah dalam pembelajaran yang dipandang dapat membantu guru dalam proses pembe-lajaran.

Dalam pembelajaran, beberapa masalah sering dialami guru, untuk memecahkan masalah dalam pembelajaran, perlu adanya model-model pembelajaran yang bisa membantu guru dalam proses pembelajaran

Menurut Dedi, (2016, hlm.165) mengutarakan, guru yang mendidik ha-rus menguasai beberapa metode menga-jar.
Maka dari pada itu guru diharapkan untuk membuat pembelajaran lebih menarik serta memakai model yang selaras dengan pembelajaran. Sama dengan pendapat Agus.S (2019, hlm. 54), model pembelajaran bisa didefinisikan jadi kerangka konseptual yang menggambarkan prosedur sistematis dalam mengorganisasikan pengalaman belajar untuk mencapai sebu-ah tujuan belajar. Salah satunya yaitu model pembelajaran Explicit Intruction. Hal ini yang jadi latar belakang dalam penelitian, lain dari pada itu untuk saat ini belum ada yang me-makai model Explicit Intruc-tion dalam pembelajaran kawih. Pembelajaran kawih bisa disebut sukses tergantung dalam kelancaran ketika proses pembelajaran salahsatu nya yang harus ada dan dijadikan pedoman oleh guru dalam me-ngajar yaitu model pembelajaran. Model Explicit Intruction merupakan salah satu model yang bisa diterapkan dalam pembelajaran bahasa Sunda. Melewati model Explicit Intruction guru bisa mende-monstrasikan pengetahuan dan keterampilan kepada siswa menurut Shoimin, (2014 hlm.77) yang menyebutkan, model Explicit Intruction harus dirancang untuk mengem-bangkan belajar siswa. mengenai pengetahuan prosedural dan pengetahuan deklaratif yang bisa diajarkan dengan pola selangkahselangkah.

Tujuan penelitian ini untuk mendeskripsikan kemampuan ngawih Sunda klasik dan pop sebelum dan sesudah menggunakan model pembelajaran Explicit Intruction kepada siswa kelas XI KPU-2 SMK Negeri 12 Bandung.

\section{METODE}

Dalam penelitian ini digunakan pendekatan kuantitatif serta metode kuasi eksperimen. Kamsinah, (2018, hlm.102) mengutarakan, setiap pendidik sebelumnya harus bisa memilih metode apa yang tepat untuk dipakai, yang bisa mempengaruhi hasil belajar ke arah yang lebih baik serta relevan dengan materi pembelajaran yang akan disampaikan. 
Metode kuasi eksperimen atau dise-but juga eksperimen semu, yaitu satu penelitian menggunakan kelas eksperimen serta tidak memakai kelas kontrol Nazir (2014, hlm. 73). Menurut Arikunto (2013, hlm.123) metode kuasi ekspe-rimen dibagi jadi tiga bagian, yaitu: : 1) one shot case study; 2) pre-test and post-test; 3) static group comparison.

Desain yang dipakai dalam penelitian ini yaitu pre-test jeung post-test. Penelitian ini dilakukan dengan cara memberi pre-test yang selanjutnya diberi tretment supaya melatih kemampuan siswa dalam kawih serta menggunakan model Explicit Intruction, yang selanjutnya dilakukan post-test. Desain seperti di-bawah ini.

\begin{tabular}{|c|c|c|}
\hline $\mathbf{O}_{1}$ & $\mathbf{X}$ & $\mathbf{O}_{\mathbf{2}}$ \\
\hline \multicolumn{3}{|c|}{ Bagan 1 } \\
Desain Penelitian pre-test dan \\
post-test \\
Arikunto, (2013 hlm.124)
\end{tabular}

keterangan:

O1 = Pre-test (kemampuan ngawih sebelum menggunakan model Explicit Intruction).

$\mathrm{X}=$ treatment pembelajaran menggunakan model Explicit Intruction.

$\mathrm{O} 2=$ Post-test (kemampuan ngawih menggunakan model Explicit Intruction).

Teknik penelitian ini dipakai untuk mengumpulkan hasil (tes), dilaksanakan sebelum dan setelah menggunakan model Explicit Intruction dalam pembe-lajaran kawih. Tes sebelum menggu-nakan model Explicit Intruction maksudnya untuk mengetahui kemampuan siswa sebelum diberi teori mengenai Explicit Intruction, sedangkan tes ahir untuk mengetahui hasil belajar siswa setelah menggunakan model Explicit Intruction.

\section{HASIL DAN PEMBAHASAN}

Berdasarkan hasil penelitian yang dibahas, ada empat hal, yaitu: 1) kemampuan ngawih Sunda siswa kelas XI KPU- 2 SMK Negeri 12 Bandung sebelum menggunakan model Explicit Intruction tahun ajaran 2018/2019, 2) kemampuan ngawih Sunda siswa kelas XI-KPU 2 SMK
Negeri 12 Bandung setelah menggunakan model Explicit Intruction tahun ajaran 2018/2019, 3) apakah ada peningkatan ngawih Sunda siswa kelas XI KPU 2 SMK Negeri 12 Bandung sebelum dan sesudah menggunakan model Explicit Intruction, dan 4) bedanya kemampuan ngawih Sunda siswa kelas kelas XI-KPU 2 SMK Negeri 12 Bandung tahun ajar 2018/2019 sebelum dan setelah menggunakan model pembelajaran Explicit Inruction.

\section{Kemampuan Ngawih Siswa Sebelum Menggunakan Model Pembelajaran Explicit Intruction}

Kemampuan ngawih Sunda siswa kelas XI-KPU 2 SMK Negeri 12 Bandung dalam ngawih Sunda ada 2 aspek yang dinilai, yaitu 1) ekspresi dan 2) tehnik vokal.

Dalam menentukan hasil nilainya menggunakan kriteria KKM dibawah ini.

Nilai $\leq 65$ siswa dianggap belum mampuh ngawih.

Nilai $\geq 65$ siswa dianggap mampuh ngawih.

Berdasarkan hasil tes, kemampuan ngawih Sunda siswa kelas XI-KPU 2 SMK Negeri 12 Bandung sebelum menggunakan model Explicit Intruction bisa diilihat dari aspek-aspeknya, kemampuan ngawih Sunda sebelum menggunakan model Explicit Intruction bisa dideskripsikan seperti di bawah ini.

\section{Ekspresi}

Kemampuan siswa ngawih aspek ekspresi sebelum menggunakan model pembelajaran Exlicit Intruction tergolong kurang, rata-rata nilai yaitu 1,6. Artinya siswa masih banyak yang tidak menggunakan penghayatan yang sesuai dengan kawih yang ditampilkan.

\section{Teknik Vokal}

Kemampuan siswa dalam ngawih Sunda aspek teknik vokal sebelum menggunakan model pembelajaran Explicit Intruction tergolong kurang, rata-rata 
yaitu 0,8. Artinya teknik vokal yang diucapkan tidak jelas a,i,u,e,o-nya, masih banyak yang belum berani menge-luarkan suaranya yang mengakibatkan suara tidak jelas. Agar lebih jelas bisa di lihat dalam grafik 1

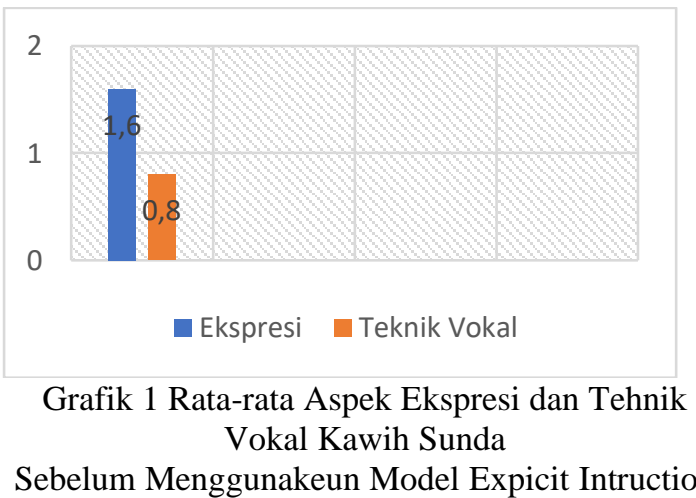

Berdasarkan pembahasan hasil yang dijelaskan, bisa disimpulkan siswa belum mampu dalam aspek ekspresi dan teknik vokal. Hal ini bisa dilihat dari rata-rata ngawih Sunda aspek ekspresi 1,6 yang skor maksimumnya 5, dan rata-rata aspek teknik vokal 0,8 yang skor maksimumnya 5 .

Dalam semua hasil sebelum menggunakan model pembelajaran Explicit Intruction dari 34 siswa memiliki rata-rata nilanya 30,14 di bawah KKM 65. Maka dari pada itu, bisa disimpulkan kemampuan siswa kelas XI KPU-2 SMK Negeri 12 Bandung sebelum menggu-nakan model Explicit Intruction belum tuntas. Agar lebih jelas bisa dilihat grafik 2 dibawah ini.

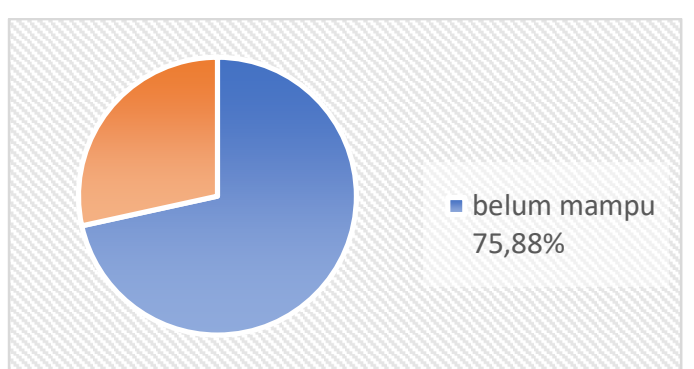

Grafik 2 Presentase kemampuan ngawih sebelum menggunakan Model Explicit Intruction

\section{Kemampuan Ngawih Siswa Setelah Menggunakan Model Pembelajaran Explicit Intruction}

Kemampuan ngawih Sunda siswa kelas XI-KPU 2 SMK Negeri 12 Bandung dalam ngawih Sunda ada 2 aspek yang dinilai, yaitu 1) ekspresi dan 2) tehnik vokal.

Dalam menentukan hasil nilainya menggunakan kriteria KKM dibawah ini.

Nilai $\leq 65$ siswa dianggap belum mampuh ngawih.

Nila $\geq 65$ siswa dianggap mampuh ngawih

Berdasarkan hasil tes, kemampuan ngawih Sunda siswa kelas XI-KPU 2 SMK Negeri 12 Bandung setelah menggunakan model Explicit Intruction bisa dilihat dari aspek-aspeknya, kemampuan ngawih Sunda setelah menggunakan model Explicit Intruction bisa dideskripsikan seperti di bawah ini.

\section{Ekspresi}

Kemampuan siswa ngawih aspek ekspresi setelah menggunakan model pembelajaran Exlicit Intruction tergolong bagus, rata-rata nilai yaitu 3,8. Artinya siswa sudah berani meng-gunakan penghayatan yang sesuai dengan kawih yang ditampilkan.

\section{Teknik Vokal}

Kemampuan siswa dalam ngawih aspek teknik vokal sesudah menggu-nakan model pembelajaran Explicit Intruction bagus, rata-rata yaitu 2,6. Artinya teknik vokal yang diucapkan sudah jelas a,i,u,e,onya, seterusnya sudah berani mengeluarkan suara yang jelas.

Berdasarkan pembahasan hasil yang dijelaskan, bisa disimpulkan siswa sudah mampu dalam aspek ekspresi dan teknik vokal. Hal ini bisa dilihat dari rata-rata ngawih Sunda aspek ekspresi 3,8 yang skor maksimumnya 5, dan rata-rata aspek teknik vokal 2,6 yang skor maksimumnya 5. Agar lebih jelas bisa dilihat dalam grafik 3 . 


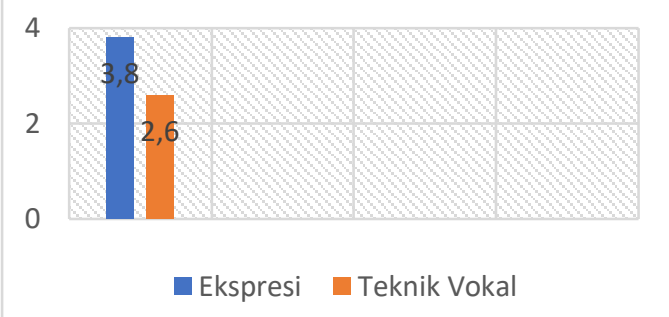

Grafik 3 Rata-rata Aspek Ekspresi dan Teknik Vokal Kawih Sunda

Setelah menggunakan Model Expicit Intruction

Berdasarkan pembahasan hasil yang dijelaskan, bisa disimpulkan siswa sudah mampu dalam aspek ekspresi dan teknik vokal. Hal ini bisa dilihat dari rata-rata ngawih Sunda aspek ekspresi 3,8 yang skor maksimumnya 5, dan rata-rata aspek teknik vokal 2,6 yang skor maksimumnya 5 .

Dalam semua hasil setelah menggunakan model pembelajaran Explicit Intruction dari 34 siswa memiliki rata-rata nilanya 75,88 di atas KKM 65. Maka dari pada itu, bisa disimpulkan kemampuan siswa kelas XI KPU-2 SMK Negeri 12 Bandung setelah menggunakan model Explicit Intruction sudah tuntas. Agar lebih jelas bisa dilihat grafik 4 dibawah ini.

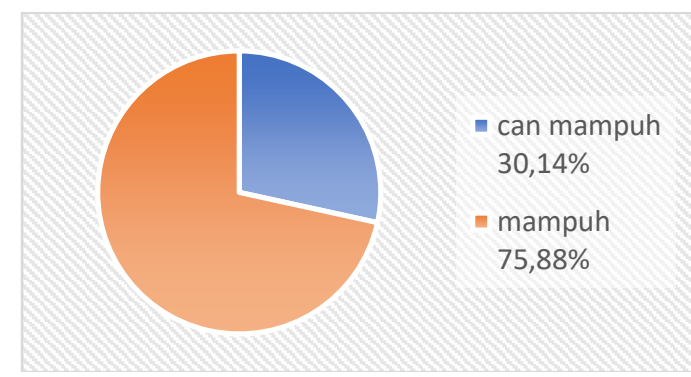

Grafik 4 Presentase Kemampuan Ngawih Setelah Menggunakan Model Explicit Intruction

\section{Meningkatnya Kemampuan Ngawih Sunda}

Kemampuan ngawih Sunda siswa kelas XI KPU-2 SMK Negeri 12 Bandung dalam ngawih Sunda ada dua 2 aspek yang di nilai, yaitu, 1) Ekspresi, dan 2) Tehnik Vokal. Adapula dalam menentukan hasil nilai dalam menen-tukan hasil nilainya menggunakan KKM dibawah ini.

Nilai $\leq 65$ siswa dianggap belum mampuh ngawih.
Nilai $\geq 65$ siswa dianggap mampuh ngawih

Dalam hasil tes meningkatnya antara kemampuan ngawih Sunda sebelum dan setelah menggunakan model Explicit Intruction. Untuk lebih jelasnya bisa dilihat grafik 5 di bawah ini.

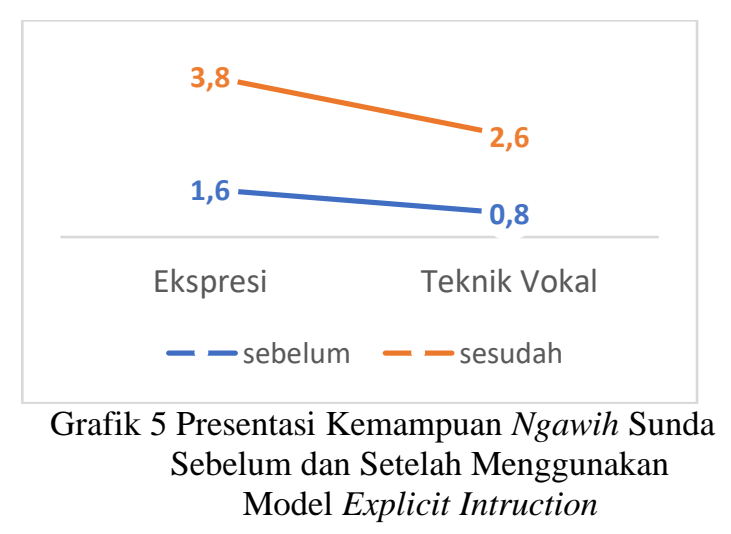

Berdasarkan grafik 5 dijelaskan kemampuan ngawih Sunda sebelum dan setelah menggunakan model Explicit Intruction, dilihat dari hasil gabungan nilai sebelum dan setelah menggunakan model Explicit Intruction yaitu rata-rata nilainya 30,14. Selanjutnya setelah menggunakan model Explicit Intruction rata-rata nilainya 75,88. Dari kemam-puan ngawih sunda ada peningkatan dari aspek ekspresi nilai ratarata 1,6 mening-kat menjadi 3,8 yang skor maksimalnya 5. Aspek tehnik vokal dari 0,8 setelah menggunakan model Explicit intruction rata-rata nilainya menjadi 2,6 yang skor maksimal nya 5 .

Bisa disimpulkan kemapuan ngawih Sunda siswa kelas XI KPU-2 SMK Negeri 12 Bandung Tahun Ajaran 2018/2019 setelah menggunakan model Explicit Intruction bisa meningkat.

\section{Perbedaan kemampuan Ngawih Sunda Sebelum dan Setelah Menggunakan Model Explicit Intruction}

Perbedaan kemampuan ngawih Sunda sebelum dan setelah menggu-nakan model Explicit Intruction dilakukan dengan cara menguji sipat data yang dilakukan terdiri dari uji normalitas sebelum dan 
setelah menggunakan mo-del Explicit Intruction serta uji homoginitas.

Uji normalitas memiliki tujuan untuk meyakinkan data kemampuan ngawih Sunda siswa kelas XI KPU-2 SMK Negeri 12 Bandung memunyai distribusi yang normal atau tidak normal. Uji normalitas Pre-test dan Post-test dalam penelitian ini menggunakan Software SPSS versi 18 dengan meng-gunakan uji Kolmogorovsmirnov. Seperti tabel dibawah ini.

Tabel 1

Analisis Hasil Pre-Test dan Post-Test

One-Sample Kolmogorov-Smirnov Test

\begin{tabular}{|ll|l|}
\hline & & Unstandardized Residual \\
\hline $\mathrm{N}$ & & 34 \\
Normal Parameters ${ }^{\mathrm{a}, \mathrm{b}}$ & Mean &, 0000000 \\
& Std. Deviation & 6,16021117 \\
Most Extreme Differences & Absolute &, 203 \\
& Positive &, 203 \\
& Negative &,- 126 \\
Kolmogorov-Smirnov Z & & 1,184 \\
Asymp. Sig. (2-tailed) & &, 121 \\
\hline
\end{tabular}

a. Test distribution is Normal.

b. Calculated from data.

Keterangan

$\mathrm{H}_{\mathrm{o}}$ : contoh populasi distribusi normal

$\mathrm{H}_{1}$; contoh populasi distribusi tidak normal

Kriteria:

$\mathrm{H}_{\mathrm{o}}$ ditarima atau $\mathrm{H}_{1}$ ditolak, jika signifikansi (sig) $\geq 0,05$

$\mathrm{H}_{1}$ ditarima atawa $\mathrm{H}_{\mathrm{o}}$ ditolak, jika nilai signifikansi $($ sig $) \leq 0,05$

Sebab (n) atau jumlah siswa 34. Maka daripada itu uji normalitas dari data pre-test menggunakan uji normalitas Kolmogorov-Smirnov, yaitu 0,121 atau lebih dari $0,05 . \mathrm{H}_{0}$ diterima atau $\mathrm{H}_{1}$ ditolak. Bisa disimpulkan yaitu contoh populasi distribusi normal. Sebab datanya dependen dan normal, maka dari itu harus diteruskan dengan menguji homogenitas.

Uji hipotesis dilaksanakan setelah menghitung uji normalitas dan uji homogenitas. Uji hipotesis memiliki tujuan untuk mengetahui hipotesis mana yang diterima dan mana yang ditolak. Dikarenakan distribunya normal, akan dilakukan uji parametric serta meng-gunakan t-test, bisa dilihat dari tabel 2 dibawah ini.

Tabel 2

Paired Samples Statistics

\begin{tabular}{|ll|c|c|c|c|}
\hline & & Mean & $N$ & Std. Deviation & Std. Error Mean \\
\hline \multirow{2}{*}{ Pair 1 } & pretest & 30,15 & 34 & 6,570 & 1,127 \\
& posttest & 75,88 & 34 & 8,570 & 1,470 \\
\hline
\end{tabular}

Dari hasil data diatas bisa dilihat rata-rata nilai pre-test 30,15 oleh standar deviasi 6,570 dan rata-rata nilai post-test yaitu 75,88 oleh standar deviasi 8,570.
Artinya nilai pre-test lebih besar dari pada rata-rata nilai post-test. 
Tabel 3

Paired Samples Test

Paired Samples Test

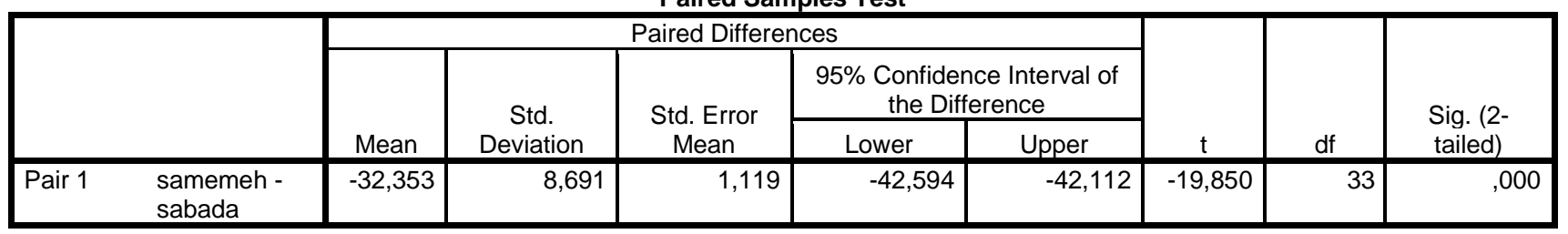

Hipotesis:

$\mathrm{H}_{0}=$ tidak ada perbedaan signifikan antara kemampuan ngawih sunda sebelum dan setelah menggunakan model Explicit Intruction .

$\mathrm{H}_{1}=$ ada perbedaan yang signifikan antara kemampuan ngawih sunda sebelum dan setelah menggunakan model Explicit Intruction.

Kriteria:

$\mathrm{H}_{0}=$ diterima atau $\mathrm{H}_{1}$ ditolak, jika nilai signifikan (sig.) $0 \geq 0,05$.

$\mathrm{H}_{1}=$ diterima atau $\mathrm{H}_{0}$ ditolak, jika nilai signifikan (sig.) $\leq 0,05$.

Berdasarkan hasil uji Paired Sample Test di atas, bisa disimpulkan hasil menghitung statistika menghasilkan 30,298 yaitu $(0,000<0,05)$ atau kurang dari 0,05 , maka daripada itu, $\mathrm{H}_{1}$ diterima atau $\mathrm{H}_{0}$ ditolak. Ada perbedaan yang signifikan antara kemampuan ngawih sunda yang menilai 2 aspek yaitu aspek ekspresi dan aspek teknik vokal sebelum dan setelah menggunakan model Explicit intruction bisa meningkatkan kemampuan ngawih sunda siswa kelas XI KPU2 SMK Negeri 12 Bandung Tahun Ajaran 2018/2019.

Dari pembahasan hasil penelitian ini dilaksanakan untuk membuktikan ada perbedaan yang signifikan antara kemampuan ngawih siswa kelas XI KPU-2 SMK Negeri 12 Bandung Tahun Ajaran 2018/2019 sebelum dan setelah menggunakan model Explicit Intruction awalnya terlihat kemampuan ngawih belum ada yang tuntas dari KKM. Hal ini terlihat setelah melaksanakan pre-test dan post test.

Kemampuan ngawih Sunda sebelum menggunakan model Explicit Intruction tergolong belum mampu dengan rata-rata nilai 30,14 dari 34 siswa belum mencapai KKM. Serta skor teratasnya yaitu 50 sedangkan skor terbawah yaitu 20. Siswa belum mampuh dari semua aspek, yaitu dari aspek ekspresi dan tehnik vokal. Hal ini bisa dilihat dari rata-rata ngawih Sunda ekspresi dengan rata-rata nilai 1,6 yang skor maksimalnya 5, dan aspek teknik vokal ratarata 0,8 yang skor maksimalnya 5 .

Kemampuan ngawih Sunda setelah menggunakan model pembelajaran Explicit Intruction tergolong mampuh dengan rata-rata nilai yaitu, 75,88. Dari 34 siswa. rata-rata siswa sudah mencapai KKM. Serta skor teratas yaitu 90, ada 2 siswa yang belum mampu dengan skor 50.

Berdasaran hasil sebelum dan setelah skor yang dicapai siswa merupakan akumulasi dari 2 aspek yang di nilai untuk mengukur kemampuan $n g a-$ wih Sunda yang meliputi aspek ekspresi dan aspek tehnik vokal.

\section{SIMPULAN}

Berdasarkan hasil penelitian dan pembahasan hasil analisis kemampuan ngawih Sunda dengan menggunakan model Explicit Intruction siswa kelas XI KPU-2 SMK Negeri 12 Bandung Tahun Ajaran 2018/2019 di bawah ini.

Kemampuan ngawih Sunda bisa meningkatkan menggunakan model $E x$ plicit Intruction, yang menilai aspek ekspresi dan tehnik vokal dalam kemampuan ngawih Sunda, sama dengan pendapat Shoimin (2014, hlm.77) yang 
menjelaskan model explicit intruction yaitu cara yang efektif untuk mengajarkan pengetahuan faktual dan keterampilan.

Kemampuan ngawih Sunda secara umum siswa kelas XI KPU-2 SMK Negeri 12 Bandung Tahun Ajaran 2018/2019 sebelum dan setelah menggunakan model Explicit intruction dianggap belum mampu serta hasil ratarata data sebelum yaitu 30,14 hal ini terlihat dari 34 siswa, termasuk kategori belum mampu. Kemampuan ngawih Sunda siswa kelas XI KPU-2 SMK Negeri 12 Bandung Tahun Ajaran 2018/2019 setelah menggunakan model Explicit intruction dianggap sudah mampu serta hasil rata-rata 75,88 , artinya siswa sudah mampu ngawih, terlihat dari 34 siswa, hanya 2 siswa yang dikategorikan belum mampu, sedangkan 32 siswa termasuk kategori mampu.

Ada peningkatan antara kemampuan ngawih sunda siswa kelas XI KPU2 SMK Negeri 12 Bandung Tahun Ajaran 2018/2019 sebelum dan setelah menggunakan model Explicit intruction. Hal itu bisa terlihat dari meningkatnya hasil data sebelum yaitu 30,14 dan data 75,88 setelah diterapkan model Explicit Intruction dalam pembelajaran kawih. Artinya besar pengaruhnya model Explicit Intructon dalam meningkatkan kemampuan ngawih. Sama dengan pendapat yang mengatakan bahwa model $E x$ plicit Intruction merupakan cara efektif untuk mengajarkan konsep dan keterampilan-keterampilan yang eksplisit kepada siswa.

Perbedaan uji hipotesis menunjukan $t_{\text {tung }}>t_{\text {tabel }}$ atau 30,298 $>1,51$. Artinya hipotesis diterima. Dari hasil penelitian, bisa disimpulkan ada perbedaan yang signifikan kemampuan ngawih Sunda siswa kelas XI KPU-2 SMK Negeri 12 Bandung tahun Ajaran 2018/19 antara sebelum dan setelah meng-gunakan model Explicit Intruction.

\section{UCAPAN TERIMA KASIH}

Segala puji dan syukur kita curahkan kepada Allah Swt. dengan rahmat dan hidayah-nya artikel ini bisa selesai. Terimakasih kepada semua pihak yang membantu dari mulai mengumpulkan data dan proses analisi artikel ini. Semoga artikel ini membawa manfaat untuk guru, siswa, dan pembaca. Maka daripada itu peneliti menantikan kritik atau saran yang membangun untuk artikel ini bisa lebih sempurna di waktu yang lain.

\section{CATATAN PENULIS}

Penulis menyatakan bahwa tidak ada konflik kepentingan terkait publikasi artikel ini. Penulis mengkonfirmasi bahwa data dan artikel ini bebas plagiarisme.

\section{PUSTAKA RUJUKAN}

Arikunto. (2013). Prosedut Penelitian Suatu Pendekatan Praktik. Jakarta: Rineka Cipta.

Aris, S. (2014). 68 Model Pembelajaran Inovatif dalam Kurikulum 2013. Yogyakarta: Ar-Ruzz Media.

Danny, S. (2010). Pengaruh Musik terhadap Konsentrasi Belajar siswa Kelas 2 SMUK 1 Salatiga. Vol. 52(1). Retrieved from https://jurnal.lppmunindra.ac.id.

Dedi, Y. (2016). Pengaruh Penerapan Metode Pembelajaran Resitasi Terhadap Hasil Belajar Matematika Siswa. 2(2), 165-174. Retrieved from http://jurnal.lppmunindrat.ac.id

Emda, A. (2017). Kedudukan Motivasi Belajar Siswa Dalam Pembelajaran. Vol. 5, 172-182. Lantanida Journl. Retrieved from https://jurnal.lppmunindra.ac.id.

Hendrayana, D. (2017). Metode Tiga Langkah Mengajar Bahasa Sunda Dengan Materi Kawih asuh 
Barudak. Loka Basa, 8(1). 22-29 Retrieved from ejournal.upi.edu/index.php/lokabas a/article/view/15963

Kamsinah. (2018). Metode Dalam Proses Pembelajaran Studi Tentang Ragam dan Implementasinya. 11(1), 101-104 Retrieved from http://journal.uinalauddin.ac.id/index.php/lentera_p endidikan/article/view/3767.

Nazir, M. (2014). Metode Penelitian. Bogor: Ghalia Indonesia.

Saeful, Agus. (2017). Penerapan Model Pembelajaran Explicit Intruction untuk Meningkatkan Hasil Belajar Siswa Pokok Bahasan Cahaya dan
Sifatnya Pada Siswa Kelas V di SD Negeri 1 Sembawa. Vol. 4(1), 1-5 Retrieved from http://jurnal.upmk.ac.id/index.php/ lensapendas/article/view/488.

Pramudita, H (2013). Model Supervisi Klinis Pengawas dan MGMP Bahasa Sunda untuk Meningkatkan Kompetensi Guru Bahasa Sunda dalam Merencanakan Pembelajaran. LOKABASA, 4, (1), 67-71. Retrieved from http://ejournal.upi.edu/index.php/l okabasa/article/view/15963 